\title{
ANÁLISE DA SAÚdE PÚBLICA NO MUNICÍPIO DE TABOÃO DA SERRA - SÃO PAULO
}

\author{
ANALYSIS OF THE PUBLIC HEALTH IN TABOÃO DA SERRA MUNICIPALITY-SÃO \\ PAULO
}

\author{
Vanini Mandaj ${ }^{1}$ \\ Viviana Mendes Lima²
}

Resumo: Neste trabalho foi realizada uma análise da saúde pública do município de Taboão da Serra segundo os dados dos sistemas de informações em saúde do Brasil. O município da região sudoeste da Região Metropolitana de São Paulo apresenta-se como o quinto menor município do estado e a segunda maior densidade demográfica do estado. Taboão da Serra mostra uma transição demográfica com uma população cada vez mais envelhecida e uma transição epidemiológica, deixando de lado as morbidades crônicas transmissiveis, para dar lugar a morbidades crônicas não-transmissíveis. Superou a expectativa do milênio na redução da taxa de mortalidade infantil e investe em saúde um valor maior que o desejável segundo a EC 29/2000 e Lei 141/2012. Apresenta uma estrutura física de rede de atendimento ampla e em construção, como acontece com a Estratégia de Saúde da Família e é referência regional de alguns serviços de saúde, com carência de recursos humanos. Prioriza programas em saúde para melhorar a qualidade de vida da população e diminuir as estatísticas preocupantes ainda de morbidade, mortalidade por causas específicas, infantil e materno-infantil.

Palavras-chave: Taboão da Serra; saúde pública; estatísticas em saúde.

Abstratc: In this assignment was accomplished a analysis of the public health in Taboão da Serra municipality was accomplished according to data from health information system of Brazil. The southwestern municipality from São Paulo Metropolitan Region presents itself as thefifth smallest municipality in the State and the one with the second biggest demographic density in the State. Taboão da Serra demonstrates a demographic transition with an increasing in the elder population and a epidemiological transition, leaving aside the transmissible chronic morbidities and giving place to nottransmissible chronic morbidities. It exceeded expectations of the millennium by reducing the rate of child mortality and it invests on health with a amount more than expected according to EC 29/2000 and Law 141/2012. It presents a physical structure of a broad attendance network and under construction, as it happens with the Family Health Strategy and is regional reference in some health services, with lack of human resources. It priories health programs to improve the quality on the population's life and to reduce the still alarming statistics of morbidity, mortality by specific causes, infant and maternal-infant.

Keywords: Taboão da Serra; public health; health statistics.

\section{INTRODUÇÃO}

Conhecer, estudar e analisar os dados de um território onde se vive ou trabalha, não é obrigação única do secretário de saúde, todos os envolvidos sejam eles, usuários ou profissionais de saúde, precisam ter este comprometimento. Segundo Mandaj (2016) para conhecer a realidade de um território, necessitamos de dados fidedignos que ao serem elaborados vão gerar informações para o trabalho em saúde pública e consequentemente, tornam-se ferramenta de suma importância na elaboração de políticas públicas de saúde.

\footnotetext{
${ }^{1}$ Fonoaudiologa da Prefeitura Municipal de Taboão da Serra, Brasil. E-mail: vaninimandaj@outlook.com.

2 Doutora em Saúde Global e Sustentabilidade, Laboratório de Estudos das Cidades, Universidade do Vale do Paraíba, Brasil. E-mail: geolimabrasilch@yahoo.com.br.
} 
Estes dados utilizados para o conhecimento e compreensão do território são os indicadores de saúde. "Os indicadores de saúde podem ser conceituados como o instrumental para mensurar as condições ou os níveis de saúde das populações, particularmente visando ao diagnóstico da situação de saúde e para avaliar tendências temporais e estabelecer comparações nacionais e internacionais" (ROCHA; CÉSAR; RIBEIRO, 2013).

Mandaj (2016) afirma que a partir da reflexão destes indicadores de saúde, portanto, poderemos encaminhar políticas públicas de saúde mais assertivas à necessidade da cada território.

\section{OBJETIVOS}

Caracterizar e mensurar, do ponto de vista sanitário, o território municipal de Taboão da Serra, São Paulo, através de indicadores de saúde, gerados regularmente pelos sistemas de informação em saúde.

\section{METODOLOGIA}

Realizou-se uma pesquisa bibliográfica documental descritiva da saúde pública do município de Taboão da Serra em São Paulo, a fim de verificar a problemática da saúde pública deste município entre os anos de 1991 e 2015. Para tanto, utilizou-se de dados secundários dos indicadores de saúde dos sistemas sobre informações em saúde como IBGE (2010), DATASUS, Fundação SEADE e Atlas Brasil, e uma vasta literatura histórica do município e do site da Prefeitura Municipal de Taboão da Serra (2004) O Índice de Desenvolvimento Humano Municipal (IDHM) para o mesmo período citado mostra-se como uma ferramenta para medir o grau de desenvolvimento humano deste município e compará-lo no ranking de municípios brasileiros.

Os últimos três Censos (IBGE), 1991, 2000 e 2010 foram escolhidos como padronização dos indicadores e a possibilidade de comparação entre eles. Outros sistemas utilizados são atualizados com maior periodicidade e trazem dados mais recentes como o Cadastro Nacional de Estabelecimentos em Saúde - CNES.

\section{DESENVOLVIMENTO}

\subsection{O Município}

Taboão da Serra é um município brasileiro do estado de São Paulo, localizado na sub-região sudoeste da Região Metropolitana de São Paulo (RMSP). A Figura 1 apresenta a localização geográfica do município e adjacências. 
Figura 1 - Mapa de localização geográfica da área de estudo.

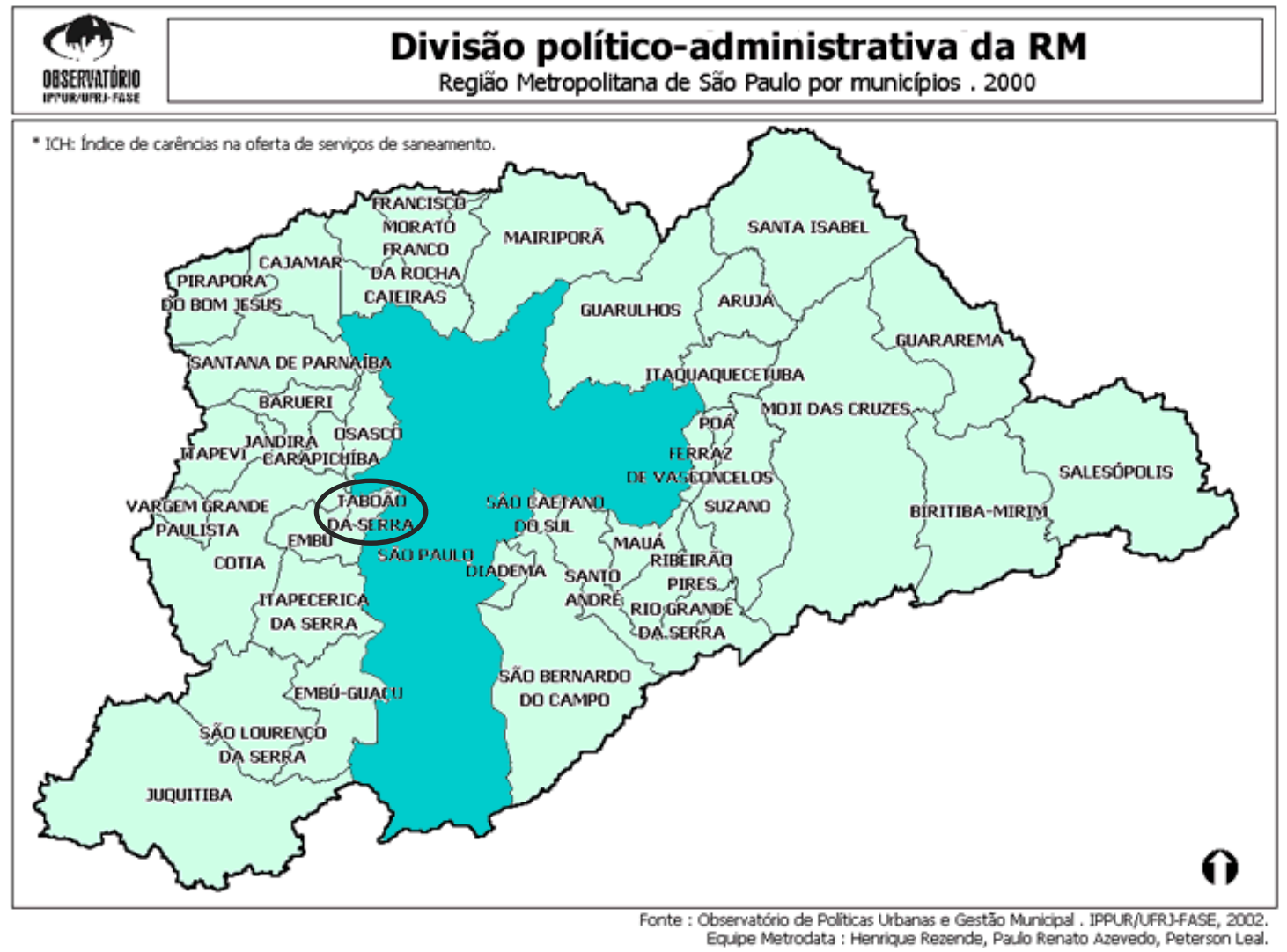

Fonte: Observatório IPPUR /UFRJ-FASE, 2000.

Localizado fora da área de mananciais, possui um terreno acidentado e cortado por inúmeros córregos que deságuam na Bacia do Pirajuçara. É transverso pela Rodovia Régis Bittencourt (BR -116), principal via de acesso local e uma das principais vias de ligação ao sul do país. É o quinto menor município em área geográfica do Estado de São Paulo, com uma área de 20,388 Km2 e o segundo maior município em densidade demográfica, 12.049,90 hab/Km2, do Estado de São Paulo, segundo o IBGE, Censo (2010). Atualmente, sua população de 244.528 habitantes, segundo o IBGE (BRASIL, 2010), vive em zona urbana, perfazendo uma taxa de urbanização de $100 \%$ e ocupa a posição 2380 entre os municípios brasileiros segundo o IDHM (2010).

O relevo da região caracteriza-se por duas unidades geomorfológicas, que são a Província do Planalto Atlântico e a Zona do Planalto Paulistano. Assim como toda a região Metropolitana, a cidade se desenvolveu ao longo da Bacia Sedimentar de São Paulo, onde existe um relevo suave na parte central com colinas e áreas de morros cristalinos, como na divisa de município, onde se localiza a Morraria do Embu. Possui um clima classificado como tipo "C", ou seja, subtropical, o que propicia fortes chuvas durante o verão e um inverno seco. A temperatura média anual é de $18,3{ }^{\circ} \mathrm{C}$ e a pluviosidade média anual é de $1465 \mathrm{~mm}$ Climate (2016). A história de Taboão da Serra inicia-se nos séculos XVI e XVII, quando a região fazia parte da rota dos bandeirantes paulistas que viviam na região do centro de São Paulo. Muitos bandeirantes passavam 
pelo município em busca de índios para escravizá-los ao mesmo tempo, esta região servia de rota tanto para o litoral paulista, e era ponto de passagem para a Região Sul do Brasil. Os jesuítas para proteger os índios dos bandeirantes paulistas criaram áreas de proteção para os nativos em terras que hoje pertencem aos municípios de Taboão da Serra e Embu (GONCALVES, 1994).

\section{Saúde em Taboão da Serra.}

Nas décadas de 80 e 90, o setor de saúde foi ampliado e aprimorado, com o Pronto Atendimento do Parque Assunção, o Hospital e Maternidade da Antena e postos de saúde. Na década de 1990, começa a funcionar o Hospital Geral do Pirajussara, do Governo do Estado, para atender toda aquela região que abrange também o município de Embu. O sistema de saúde do município de Taboão da Serra é regionalizado e hierarquizado tendo como porta de entrada no sistema, as Unidades Básicas de Saúde e Pronto-Socorros. As UBS do município de Taboão da Serra atuam dentro de um processo de territorialização, com as áreas de abrangência, estabelecidas a partir do estudo de utilização dos serviços pela população (SARGSUS, 2012).

Secretaria Municipal de Saúde apresenta a composição da Rede Pública de Saúde de Taboão da Serra, (2015), é composta conforme Tabela 1.

Tabela 1 - Estrutura da Secretaria de Saúde em Taboão da Serra.

\begin{tabular}{l|l}
\hline \multicolumn{2}{c}{ COMPOSIÇÃO DA SECRETARIA MUNICIPAL DE SAUDDE DE } \\
TABOÃO DA SERRA \\
\hline 01 & Centro de Especialidades Médicas ligado a uma das Unidades Básicas \\
\hline 01 & Pronto-Atendimento (Gestão por OS); \\
\hline 01 & Unidade Mista com Pronto Socorro e Maternidade (Gestão por OS); \\
\hline 01 & Pronto Socorro Infantil (Gestão por OS); \\
\hline 01 & Hospital Geral (Administração Estadual via OS); \\
\hline 01 & Ambulatório Médico Especializado (Administração Estadual via OS); \\
\hline 01 & Centro de Especialidade Odontológica;; \\
\hline 01 & Centro de Referência da Mulher e Coordenadoria dos Direitos da Mulher; \\
\hline 01 & Serviço Especializado de Reabilitação; \\
\hline 01 & SAMU; \\
\hline 01 & Pronto Atendimento Domiciliar; \\
\hline 01 & CAPSi; \\
\hline 01 & CAPS AD; \\
\hline 01 & CAPS II ( em habilitação) \\
\hline 01 & Centro de Convivência e Cultura; \\
\hline 01 & Farmácia Popular; \\
\hline 01 & Serviço de Atendimento Especializado DST/AIDS; \\
\hline 01 & Vigilância em Saúde/Centro de Zoonoses. \\
\hline 13 & Unidades Básicas de Saúde \\
\hline 01 & Serviço de Verificação de Óbitos; \\
\hline 01 & Central de Regulação; \\
\hline 01 & Ouvidoria; \\
\hline
\end{tabular}

Fonte: Secretaria de Saúde de Taboão da Serra (2016). 


\subsection{Estatísticas de saúde do município}

\subsubsection{Indicadores Demográficos}

$\mathrm{Na}$ Tabela vê-se os dados populacional do município a partir dos últimos três censos o que aumentou demanda e ampliação no atendimento à saúde.

Tabela 2 - População residente segundo sexo no município de Taboão da Serra, São Paulo, Censos de 1991, 2000 e 2010.

\begin{tabular}{l|l|l|l}
\hline ANO & $\mathbf{1 9 9 1}$ & $\mathbf{2 0 0 0}$ & $\mathbf{2 0 1 0}$ \\
\hline Masculino & 78430 & 95357 & 116895 \\
\hline Feminino & 81654 & 102287 & 127633 \\
\hline Total & $\mathbf{1 6 0 0 8 4}$ & $\mathbf{1 9 7 6 4 4}$ & $\mathbf{2 4 4 5 2 8}$ \\
\hline
\end{tabular}

Fonte: Adaptado de IBGE Censos 1991, 2000 e 2010.

Figura 2 - População residente segundo sexo no município de Taboão da Serra, São Paulo, censos 1991, 2000 e 2010.

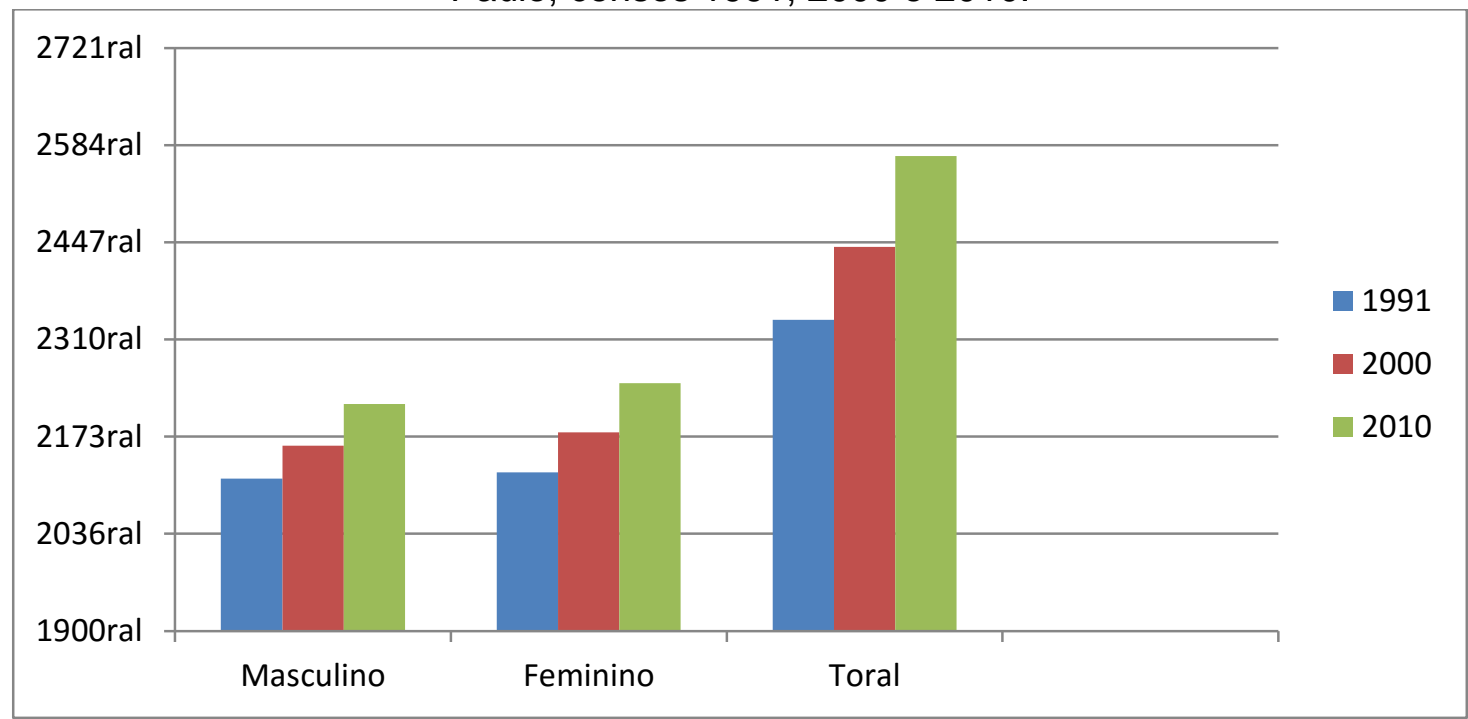

Fonte Adaptado de: IBGE Censos 1991, 2000 e 2010.

Segundo Atlas Brasil (2013), entre os anos de 1991 e 2000, a população do município, cresceu a uma taxa média anual de $2,37 \%$, enquanto no Brasil essa taxa foi de $1,63 \%$ no mesmo período. Entre 2000 e 2010, a população de Taboão da Serra cresceu a uma taxa média anual de $2,15 \%$, enquanto no Brasil foi de foi de $1,17 \%$, no mesmo período.

Para a Fundação SEADE (2015), a estimativa da população para Taboão da Serra é de 264.574 habitantes e a taxa de crescimento 2010/2015 é de 1,62\%, enquanto a taxa média anual de crescimento da Região Metropolitana de São Paulo é de $0,78 \%$ e a do Estado de São Paulo de $0,87 \%$.

Observa-se que a taxa de crescimento anual segundo dados apresentados pelos órgãos de pesquisa deTaboão da Serra vem decaindo durante os últimos períodos, 
porém, segundo a última medição, ela ainda é maior que a média brasileira em 2010. As taxas médias da Região Metropolitana e Estado de SãoPaulo em 2015, segundo dados da Fundação SEADE (2015) e a população de Taboão da Serra, SP é 100\% urbana.

Tabela 3 - Distribuição da população residente segundo faixa etária e sexo no município de Taboão da Serra, São Paulo, ano 2010.

\begin{tabular}{l|c|c|c}
\hline Faixa Etária & Masculino & Feminino & Total \\
\hline Menor 1 ano & 1947 & 1779 & 3726 \\
\hline 1 a 4 anos & 7205 & 7051 & 14256 \\
\hline 5 a 9 anos & 9483 & 9314 & 18797 \\
\hline 10 a 14 anos & 10951 & 10835 & 21786 \\
\hline 15 a 19 anos & 10042 & 10181 & 20223 \\
\hline 20 a 29 anos & 22831 & 23942 & 46773 \\
\hline 30 a 39 anos & 20375 & 22691 & 43066 \\
\hline 40 a 49 anos & 15614 & 17887 & 33501 \\
\hline 60 a 59 anos 69 anos & 10488 & 12570 & 23058 \\
\hline 70 a 79 anos & 5307 & 6803 & 12110 \\
\hline 80 anos e mais & 2064 & 3210 & 5274 \\
\hline Total & 588 & 1370 & 1958 \\
\hline
\end{tabular}

Fonte: Adaptado de IBGE Censo 2010.

A população de Taboão da Serra, São Paulo é uma população com predomínio da fase adulta. Apresenta um índice de envelhecimento em 2010 de 33,02\%, com uma estimativa para 2015 de 42,44\%, enquanto na Região Metropolitana este índice é de $60,30 \%$ e no Estado de São Paulo é de $67,20 \%$, neste mesmo ano (Fundação SEADE, 2015). Essa taxa, ainda abaixo da Região Metropolitana e do Estado de São Paulo, apresentou crescimento.

A razão de sexos observada é de 91,58, portanto, uma predominância de mulheres. A população com menos de 15 anos é de $23,95 \%$, enquanto que a população com 60 anos e mais é de $7,90 \%$.

\subsubsection{Indicadores de Estatísticas Vitais}

Tabela 4 - Nascidos vivos por residência da mãe no município de Taboão da Serra, SP segundo sexo, nos anos de 2000 e 2010.

\begin{tabular}{l|c|c|c}
\hline ANO & $\mathbf{2 0 0 0}$ & $\mathbf{2 0 1 0}$ & Total \\
\hline Masculino & 2590 & 2336 & 4926 \\
\hline Feminino & 2389 & 2176 & 4565 \\
\hline Total & $\mathbf{4 9 7 9}$ & $\mathbf{4 5 1 2}$ & $\mathbf{9 4 9 1}$ \\
\hline
\end{tabular}

Fonte: Brasil (2015). 
Figura 3 - Nascidos vivos por residência da mãe no município de Taboão da Serra, SP segundo sexo, nos anos de 2000 e 2010.

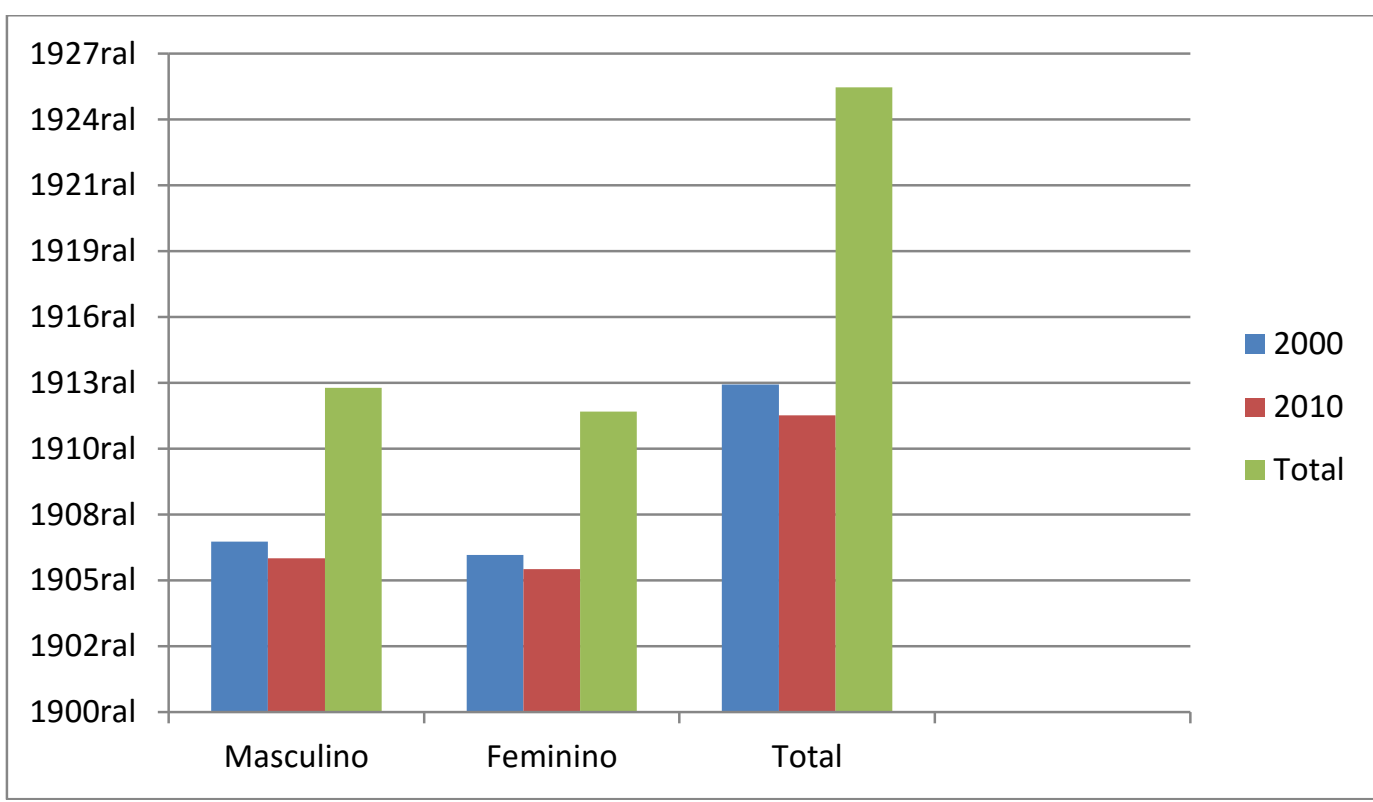

Fonte: Brasil (2015).

Observa-se uma taxa de nascidos vivos em Taboão da Serra, SP de 25,19 por mil habitantes em 2000, e 18,45 por mil habitantes em 2010, a taxa apresentou uma queda de $26,75 \%$. Segundo dados da Fundação SEADE, esta taxa encontra-se em 18,04 por mil habitantes em 2014, mostrando o seu ainda declínio, porém, esta taxa encontra-se acima da média da região metropolitana e do estado de São Paulo, 15,70 e 14,66 por mil habitantes, respectivamente. Observamos também, a predominância do sexo masculino nos nascimento.

Tabela 5 - Óbitos por residência por capítulo do CID-10 no município de Tabão da Serra, SP nos anos de 2000 e 2010.

\begin{tabular}{l|l|l|l}
\hline Capítulo CID-10 & $\mathbf{2 0 0 0}$ & $\mathbf{2 0 1 0}$ & Total \\
\hline I. Algumas doenças infecciosas e parasitárias & 47 & 48 & 95 \\
\hline II. Neoplasias (tumores) & 178 & 213 & 391 \\
\hline $\begin{array}{l}\text { III. Doenças sangue órgãos hematológicos e transtornos } \\
\text { imunitários }\end{array}$ & 9 & 3 & 12 \\
\hline IV. Doenças endócrinas nutricionais e metabólicas & 37 & 54 & 91 \\
\hline V. Transtornos mentais e comportamentais & 7 & 8 & 15 \\
\hline VI. Doenças do sistema nervoso & 21 & 39 & 60 \\
\hline IX. Doenças do aparelho circulatório & 357 & 467 & 824 \\
\hline X. Doenças do aparelho respiratório & 116 & 145 & 261 \\
\hline XI. Doenças do aparelho digestivo & 58 & 70 & 128 \\
\hline XII. Doenças da pele e do tecido subcutâneo & 1 & 2 & 3 \\
\hline XIII.Doenças sistemaosteomuscular e tecido conjuntivo & 1 & 3 & 4 \\
\hline XIV. Doenças do aparelho geniturinário & 7 & 25 & 32 \\
\hline XV. Gravidez, parto e puerpério & 1 & 1 & 2 \\
\hline XVI. Algumas afecções originadas no período perinatal & 52 & 34 & 86 \\
\hline XVII.Malformações congênitas, deformidades e anomalias & 19 & 15 & 34 \\
\hline
\end{tabular}




\begin{tabular}{l|l|l|l}
\hline cromossômicas & & & \\
\hline $\begin{array}{l}\text { XVIII.Sintomas sinais e achados anormais ex clínicos e } \\
\text { laboratoriais }\end{array}$ & 22 & 24 & 46 \\
\hline XX. Causas externas de morbidade e mortalidade & 258 & 141 & 399 \\
\hline Total & $\mathbf{1 1 9 1}$ & $\mathbf{1 2 9 2}$ & $\mathbf{2 4 8 3}$ \\
\hline
\end{tabular}

Fonte: Brasil (2015).

Figura 4 - Óbitos por residência por capítulo do CID-10 no município de Taboão da Serra, SP nos anos de 2000 e 2010.

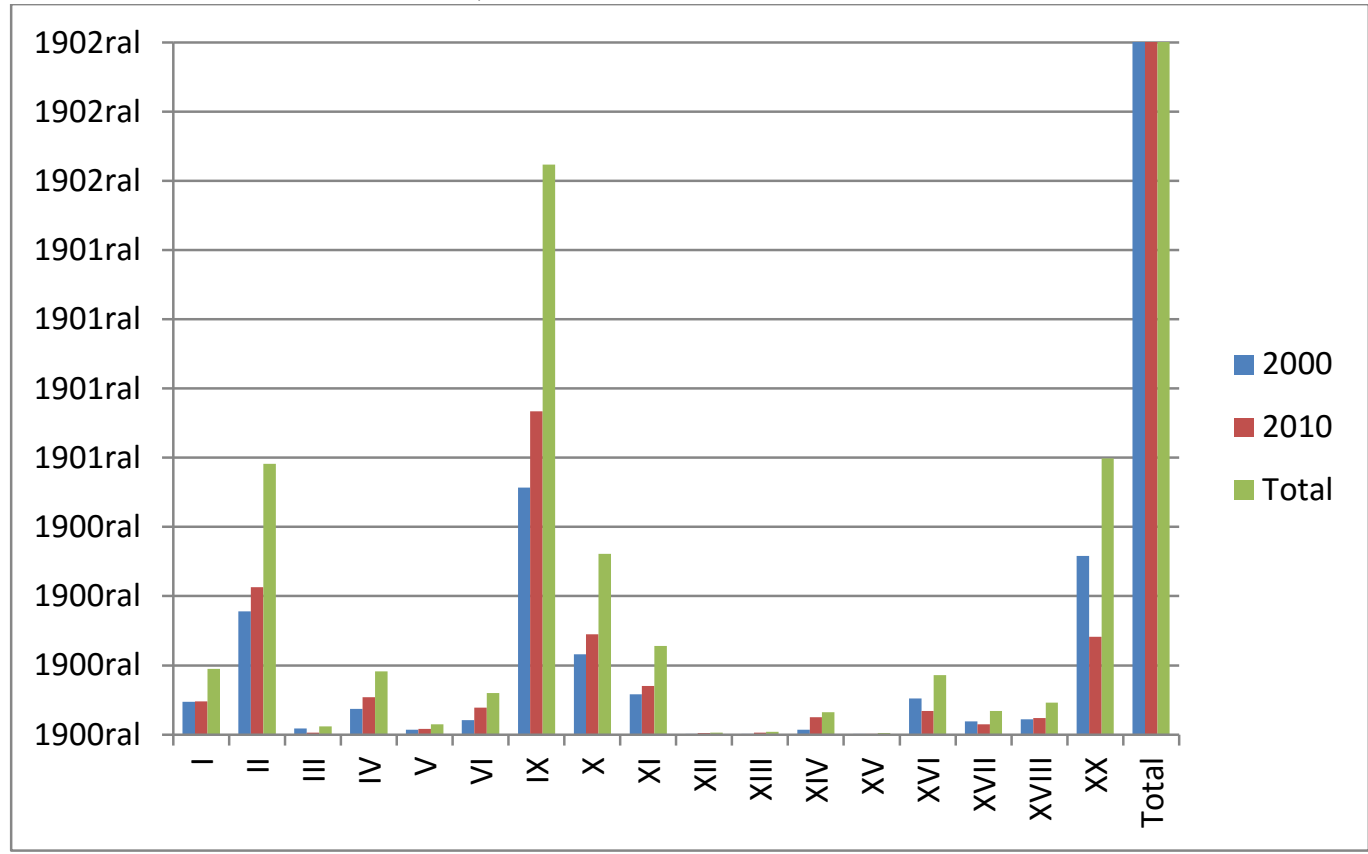

Fonte: Brasil (2015).

Observa-se uma taxa de mortalidade geral em Taboão da Serra em 2000 de 6,02 por mil habitantes, e 5,28 por mil habitantes em 2010, a principal causa de óbito ocorrido, tanto em 2000 quanto em 2010 foram às relacionadas às doenças do aparelho circulatório com uma taxa de mortalidade específica em 2000 de 29,97\% e $36,14 \%$ em 2010. As neoplasias que em 2000 estavam em terceiro lugar com uma taxa de 14,94\%, subiram para segundo lugar em 2010 com taxa de 16,48\%. As doenças do aparelho respiratório, que em 2000 estavam em quarto lugar com taxa de $9,13 \%$, subiram para terceiro em 2010 com uma taxa de $11,22 \%$. As causas externas que em 2000, apresentavam-se em segundo lugar com taxa de $21,66 \%$, apresentaram uma queda em 2010, e passaram a ocupar a quarta principal causa de óbito no município com taxa de 10,91\%.

Tabela 6 - Mortalidade Infantil no município de Taboão da Serra, São Paulo, anos de 2000 e 2010.

\begin{tabular}{l|c|c|c}
\hline Faixa etária & $\mathbf{2 0 0 0}$ & $\mathbf{2 0 1 0}$ & Total \\
\hline 0 a 6 dias & 45 & 34 & 79 \\
\hline 7 a 27 dias & 18 & 7 & 25 \\
\hline 28 a 364 dias & 32 & 13 & 45 \\
\hline Total & $\mathbf{9 5}$ & $\mathbf{5 4}$ & $\mathbf{1 4 9}$ \\
\hline
\end{tabular}

Fonte: Brasil (2015). 
A taxa de mortalidade infantil em Taboão da Serra, SP apresenta uma tendência de queda de $37,31 \%$, com uma taxa de 19,08 por mil habitantes em 2000, e uma taxa de 11,99 por mil habitantes em 2010. Para 2014, segundo a Fundação SEADE, esta taxa foi de 11,29 por mil habitantes., estando um pouco abaixo das taxas da região metropolitana e do estado de São Paulo com 11,41 e 11,43 por mil habitantes, respectivamente.

Tabela 7 - Óbitos de mulheres em idade fértil por faixa etária no município de Taboão da Serra, São Paulo nos anos de 2000 e 2010.

\begin{tabular}{l|c|c|c}
\hline Faixa Etária & $\mathbf{2 0 0 0}$ & $\mathbf{2 0 1 0}$ & Total \\
\hline 10 a 14 anos & 4 & 4 & 8 \\
\hline 15 a 19 anos & 4 & 4 & 8 \\
\hline 20 a 29 anos & 14 & 10 & 24 \\
\hline 30 a 39 anos & 21 & 24 & 45 \\
\hline 40 a 49 anos & 70 & 54 & 124 \\
\hline Total & $\mathbf{1 1 3}$ & $\mathbf{9 6}$ & $\mathbf{2 0 9}$ \\
\hline
\end{tabular}

Fonte: Brasil (2015).

Observa-se que houve uma queda na taxa de óbitos de mulheres em idade fértil em Taboão da Serra de 29,62\%, em 2000. Houve uma taxa de óbitos de mulheres em idade fértil de 159,48 por 100.000 habitantes, enquanto que em 2010, o óbito de mulheres em idade fértil, em Taboão da Serra, foi de 112,23 por 100.000 habitantes.Isto demonstra uma necessidade de atenção para saúde da mulher, considerando que os números apresentados são considerados elevados para o perfil municipal

\subsubsection{Indicadores de Morbidade}

Tabela 8 - Morbidade hospitalar SUS por local de internação segundo capítulo CID-10 e sexo no município de Taboão da Serra, São Paulo, dezembro 2015.

\begin{tabular}{l|l|l|l}
\hline Capítulo CID-10 & Masc & Fem & Total \\
\hline I. Algumas doenças infecciosas e parasitárias & 15 & 15 & 30 \\
\hline II. Neoplasias (tumores) & 13 & 34 & 47 \\
\hline III. Doenças sangue órgãos hematológicos e transtornos imunitários & 2 & 2 & 4 \\
\hline IV. Doenças endócrinas nutricionais e metabólicas & 3 & 11 & 14 \\
\hline V. Transtornos mentais e comportamentais & 4 & 15 & 19 \\
\hline VI. Doenças do sistema nervoso & 9 & 8 & 17 \\
\hline VII. Doenças do olho e anexos & 76 & 99 & 175 \\
\hline VIII.Doenças do ouvido e da apófise mastóide & 2 & 3 & 5 \\
\hline IX. Doenças do aparelho circulatório & 49 & 55 & 104 \\
\hline X. Doenças do aparelho respiratório & 67 & 70 & 137 \\
\hline XI. Doenças do aparelho digestivo & 80 & 72 & 152 \\
\hline XII. Doenças da pele e do tecido subcutâneo & 27 & 15 & 42 \\
\hline XIII.Doenças sistemaosteomuscular e tecido conjuntivo & 9 & 4 & 13 \\
\hline XIV. Doenças do aparelho geniturinário & 15 & 35 & 50 \\
\hline XV. Gravidez, parto e puerpério & - & 350 & 350 \\
\hline XVI. Algumas afecções originadas no período perinatal & 13 & 18 & 31 \\
\hline $\begin{array}{l}\text { XVII.Malformaçõescongenitas deformidades e anomalias } \\
\text { cromossômicas }\end{array}$ & 8 & 5 & 13 \\
\hline XVIII.Sintomas sinais e achados anormais ex clínicos e laboratoriais & 12 & 3 & 15 \\
\hline
\end{tabular}




\begin{tabular}{l|l|l|l}
\hline $\begin{array}{l}\text { XIX. Lesões envenenamento e algumasoutras conseqüências causas } \\
\text { externas }\end{array}$ & 119 & 53 & 172 \\
\hline XXI. Contatos com serviços de saúde & 1 & 10 & 11 \\
\hline Total & $\mathbf{5 2 4}$ & $\mathbf{8 7 7}$ & $\mathbf{1 4 0 1}$ \\
\hline
\end{tabular}

Fonte: Brasil (2015).

De acordo com os dados de internações hospitalares, os dados de causas ligadas à gravidez, parto e puerpério aparecem em primeiro lugar com 24,98\% das internações. As doenças dos olhos aparecem em segundo lugar com 12,49\%, seguidas pelas causas externas com 12,27\%. Em seguida as doenças do aparelho digestivo com $10,84 \%$, doenças do aparelho respiratório com $9,77 \%$, e somente em sexto lugar aparecem às doenças do aparelho circulatório com $7,42 \%$, segundo informações do Ministério da Saúde. Considerar que, neste quadro, inclui-se os atendimentos realizados no Hospital Geral do Pirajussara, de administração estadual, localizado no município e que é referência para a região e realiza cirurgias de olho e anexos.

\subsection{Rede Assistencial}

Tabela 9 - Estabelecimentos de saúde segundo o tipo de estabelecimento e tipo de gestão no município de Taboão da Serra, São Paulo, dezembro de 2015.

\begin{tabular}{l|c|c|c}
\hline Tipo de Estabelecimento & Estadual & Municipal & Total \\
\hline Central de Regulação & - & 1 & 1 \\
\hline Central de Regulação Médica das Urgências & - & 1 & 1 \\
\hline Centro de Atenção Psicossocial-CAPS & - & 3 & 3 \\
\hline Centro de Saúde/Unidade Básica de Saúde & - & 12 & 12 \\
\hline Clínica Especializada/Ambulatório Especializado & 1 & 18 & 19 \\
\hline Consultório & - & 46 & 46 \\
\hline Farmácia & - & 1 & 1 \\
\hline Hospital Especializado & - & 1 & 1 \\
\hline Hospital Geral & 1 & 2 & 3 \\
\hline Policlínica & 1 & 10 & 11 \\
\hline Pronto Atendimento & - & 1 & 1 \\
\hline Pronto Socorro Especializado & - & 1 & 1 \\
\hline Secretaria de Saúde Neré-Hospitalar- & - & 1 & 1 \\
\hline Unidade de Serviço de Apoio de Diagnose e Terapia & - & 6 & 6 \\
\hline Unidade de Vigiláncia em Saúde Nível Prénel de & - & 2 & 2 \\
\hline Unidade Móvel & 4 & 4 \\
\hline Urgência/Emergência & $\mathbf{3}$ & $\mathbf{1 1 0}$ & $\mathbf{1 1 3}$ \\
\hline Total & & & \\
\hline
\end{tabular}

Fonte: Brasil (2015).

Observando os dados, verifica-se pontos que não correspondem à realidade do município, por exemplo o baixo número de consultórios, já que estes dados incluem o dados de estabelecimentos particulares. É de conhecimento que muitos profissionais e estabelecimentos não realizam o seu registro no CNES.Possui 12 unidades básicas de saúde, o que mostra a importância que o município tem na atenção primária, justificando que uma atenção primária forte, torna um sistema de saúde forte. Ainda, 
dos três CAPSs, o CAPS infanto-juvenil, por exemplo, é referência regional para a Região dos Mananciais. Com o baixo número de recursos humanos e para manter a qualidade de saúde, Taboão da Serra tem como parceiro, uma organização social de saúde que faz a gestão do Hospital Especializado e dos 2 Prontos Socorros.

Tabela 10 - Quantidade de equipes de saúde segundo o tipo no município de Taboão da Serra, São Paulo, dezembro de 2014 e dezembro de 2015.

\begin{tabular}{l|c|c}
\hline Tipo da Equipe & $\mathbf{2 0 1 4}$ & $\mathbf{2 0 1 5}$ \\
\hline ESF-Equipe de Saúde da Família & - & 6 \\
\hline Equipe de Saúde da Família com Saúde Bucal Modalidade I & 10 & 11 \\
\hline Equipe de Agentes Comunitários de Saúde & 8 & 2 \\
\hline ENASF1-Equipe do núcleo de Apoio à Saúde da Família & 1 & 1 \\
\hline Total & $\mathbf{1 9}$ & $\mathbf{2 0}$ \\
\hline
\end{tabular}

$$
\text { Fonte: Brasil (2015). }
$$

Taboão da Serra obteve um aumento das equipes de estratégia da família, porém ainda muito além do desejável, menos da metade do número de unidades básicas de saúde. Porém, esse aumento mostra que a proximidade com a comunidade através da territorialização é considerada uma importante estratégia no município.

Tabela 11 - Informações sobre as despesas de saúde segundo indicadores, no município de Taboão da Serra, SP, nos anos de 2013, 2014 e 2015.

\begin{tabular}{|c|c|c|c|}
\hline Indicador & 2013 & 2014 & 2015 \\
\hline $\begin{array}{l}\text { Participação da receita de impostos na receita total do } \\
\text { município }\end{array}$ & $24,96 \%$ & $27,41 \%$ & $25,82 \%$ \\
\hline $\begin{array}{l}\text { Participação das transferências intergovernamentais na } \\
\text { receita total do município }\end{array}$ & $57,77 \%$ & $59,81 \%$ & $60,61 \%$ \\
\hline $\begin{array}{l}\text { Participação \% das transferências para a saúde (SUS) no } \\
\text { total de recursos transferidos para o município }\end{array}$ & $6,07 \%$ & $8,16 \%$ & $8,35 \%$ \\
\hline $\begin{array}{l}\text { Participação \% das transferências da União para a saúde } \\
\text { no total de recursos transferidos para a saúde no } \\
\text { município }\end{array}$ & $100,00 \%$ & $90,18 \%$ & $91,08 \%$ \\
\hline $\begin{array}{l}\text { Participação \% das transferências da União para a saúde } \\
\text { (SUS) no total de transferências da União para o } \\
\text { município }\end{array}$ & $23,16 \%$ & $25,77 \%$ & $27,48 \%$ \\
\hline $\begin{array}{l}\text { Participação \% da receita de impostos e transferências } \\
\text { constitucionais e legais na receita total do município }\end{array}$ & $65,83 \%$ & $67,39 \%$ & $66,71 \%$ \\
\hline $\begin{array}{l}\text { Despesa total com saúde, em } \mathrm{R} \$ / \mathrm{hab}, \text { sob } \\
\text { responsabilidade do município, por habitante }\end{array}$ & $\begin{array}{c}\mathrm{R} \$ \\
532,77\end{array}$ & $\begin{array}{c}\mathrm{R} \$ \\
586,94\end{array}$ & $\begin{array}{c}\mathrm{R} \$ \\
632,02\end{array}$ \\
\hline $\begin{array}{l}\text { Participação da despesa com pessoal na despesa total } \\
\text { com saúde }\end{array}$ & $46,35 \%$ & $48,04 \%$ & $43,88 \%$ \\
\hline $\begin{array}{l}\text { Participação da despesa com medicamentos na despesa } \\
\text { total com saúde }\end{array}$ & $0,00 \%$ & $0,00 \%$ & $0,00 \%$ \\
\hline $\begin{array}{l}\text { Participação da despesa com serviços de terceiros - } \\
\text { pessoa jurídica na despesa total com saúde }\end{array}$ & $32,06 \%$ & $41,20 \%$ & $46,77 \%$ \\
\hline $\begin{array}{l}\text { Participação da despesa com investimentos na despesa } \\
\text { total com saúde }\end{array}$ & $3,03 \%$ & $4,42 \%$ & $3,25 \%$ \\
\hline Subfunções Administrativas & $0,00 \%$ & $0,00 \%$ & $0,00 \%$ \\
\hline Subfunções Vinculadas & $100,00 \%$ & $100,00 \%$ & $100,00 \%$ \\
\hline Atenção Básica & $39,85 \%$ & $32,93 \%$ & $28,80 \%$ \\
\hline Assistência Hospitalar e Ambulatorial & $57,60 \%$ & $64,90 \%$ & $69,05 \%$ \\
\hline Suporte Profilático e Terapêutico & $2,10 \%$ & $1,71 \%$ & $1,11 \%$ \\
\hline Vigilância Sanitária & $0,11 \%$ & $0,02 \%$ & $0,12 \%$ \\
\hline
\end{tabular}




\begin{tabular}{l|c|c|c}
\hline Vigilância Epidemiológica & $0,34 \%$ & $0,44 \%$ & $0,93 \%$ \\
\hline Alimentação e Nutrição & $0,00 \%$ & $0,00 \%$ & $0,00 \%$ \\
\hline Informações Complementares & $0,00 \%$ & $0,00 \%$ & $0,00 \%$ \\
\hline $\begin{array}{l}\text { Participação das transferências para a saúde em relação } \\
\text { à despesa total do município com saúde }\end{array}$ & $14,24 \%$ & $18,12 \%$ & $17,29 \%$ \\
\hline $\begin{array}{l}\text { Participação da receita própria aplicada em saúde } \\
\text { conforme a LC141/2012 }\end{array}$ & $32,09 \%$ & $32,91 \%$ & $34,60 \%$ \\
\hline
\end{tabular}

Fonte: SIOPS (2015).

De acordo com a série histórica de indicadores, o município de Taboão da Serra apresentou um aumento de $18,62 \%$ com a despesa total de saúde. Houve uma maior transferência da União (SUS) ao município, que aumentou em 18,65\%, enquanto que as despesas com recursos próprios em saúde tiveram um aumento de $7,82 \%$ e a receita de impostos e transferências constitucionais em 1,33\%.Importante notar na tabela que o município de Taboão da Serra investe em saúde, um valor acima do desejável pela EC 29/2000 e Lei 141/2012, de 15\% (MENDES, 2016).

\section{4 Índice de desenvolvimento humano}

Índice de Desenvolvimento Humano do município de Taboão da Serra, São Paulo segundo os censos de 1991, 2000 e 2010.0 Índice de Desenvolvimento Humano (IDHM) - Taboão da Serra é 0,769, em 2010, o que situa esse município na faixa de Desenvolvimento Humano Alto (IDHM entre 0,700 e 0,799). A dimensão que mais contribui para o IDHM do município é Longevidade, com índice de 0,863, seguida de Renda, com índice de 0,742, e de Educação, com índice de 0,710.

\section{CONSIDERAÇÕES FINAIS}

Taboão da Serra é um município totalmente urbano e tem apresentado uma taxa de crescimento decrescente, porém esta taxa ainda encontra-se acima da média metropolitana e do Estado de São Paulo. Há o predomínio de adultos do sexo feminino e apresenta uma taxa de envelhecimento crescente, ainda menor que a Região Metropolitana e o Estado. Assim como o país, Taboão da Serra também passa por uma transição demográfica apresentando, atualmente, queda da taxa de natalidade e mortalidade, com uma população cada vez mais idosa.Apesar da queda crescente da taxa de natalidade, ela ainda está acima da Região Metropolitana e do Estado, com predomínio de nascimentos do sexo masculino. A mortalidade segue o padrão brasileiro de primeira causa de mortes, doenças do aparelho circulatório, seguido das neoplasias, aparelho respiratório e causas externas. Apesar dos óbitos de mulheres em idade fértil terem caído, ainda encontram-se elevados, porem amortalidade infantil apresentou uma queda considerável. Taboão da Serra cumpre assim, o objetivo do milênio para a redução da taxa de mortalidade infantil até o ano de 2015. 
Para a redução das taxas de mortalidade infantil e mulheres em idade fértil, programas em saúde e diversas ações foram de relevância no município: Comitê de Mortalidade Instituído, protocolos instituídos de atendimento ao pré-natal e puericultura, Programa materno-infantil Amor de Mãe, garantia de vacinação e exames laboratoriais no pre-natal e aumento da grade de medicamentos ofertados. Taboão da Serra também demonstra a característica nacional da transição epidemiológica, deixando as doenças transmissíveis que ocupavam a primeira causa de mortes anteriormente, para as doenças crônicas não-transmissíveis atualmente.

A morbidade segue com internações ligadas ao parto, gravidez e puerpério como principal causa, seguidas de doenças de olho e causas externas. As doenças do aparelho digestivo, aparelho respiratório e circulatório, seguem como causas subsequentemente.

Para o combate das morbidades principais, Taboão da Serra, promove programas como por exemplo,Combate à dependência química (Jogo Elos) em parceria com a Secretaria de Educação, curso de Cuidadores Informais de Idosos, Núcleo de Prevenção à Violência e Atividades físicas nas Unidades Básicas de Saúde, em parceria com a Secretaria de Esportes. Taboão da Serra é um município jovem, o quinto menor município em área geográfica e o segundo maior em densidade demográfica do Estado de São Paulo, o que gera alguns obstáculos ao seu pleno desenvolvimento. Porém, o que se observa, são dados que refletem a atual estrutura de saúde do país, como a transição demográfica e epidemiológica. Observa-se também, pelos dados pesquisados uma tendência para a construção de uma saúde pública que contemple os princípios finalisticos do SUS: universalidade, integralidade e equidade.

Um grande problema enfrentado ainda no município é sobre a transmissão de informações à comunidade. Não só de dados estatísticos que mostram a realidade, mas também das convocações às assembléias e fóruns. O site da prefeitura não traz muitas informações para a população e não incentiva a participação popular nas decisões. Uma comunicação não efetiva, deixa de transmitir a realidade e não participa a população. Essas informações devem ser anti partidárias e devem objetivar a proteção do cidadão.

O cidadão precisa ser, antes de tudo, protagonista de sua saúde e os programas em saúde devem ser capazes de construir com o indivíduo a sua capacidade de autonomia, diminuir a sua vulnerabilidade e de produzir saúde.

Duas observações devem ser pontuadas para a melhoria do sistema de saúde. A primeira é o conhecimento e a importância da utilização dos índices de saúde. $O$ desconhecimento de sua importância gera a não alimentação correta dos dados, visualizadas nas diferenças das diversas publicações. A segunda é que estas ferramentas são de difícil manuseio para a população, ou seja, imprecisas e inacessíveis. Considero os sistemas de saúde, um ponto inicial de trabalho a ser 
discutido, pois são deles que devem partir a maioria das políticas públicas de um país com dimensões gigantescas e com muitos locais de difícil acesso.

Os sistemas de saúde devem auxiliar a construção de um pensar em saúde compartilhado por todos cidadãos brasileiros, seja qual for o território. A saúde deve sempre ser vista como um bem coletivo, de direito, em permanente construção, capaz de dar ao ser humano dignidade e participe de uma comunidade. O SUS é uma solução com problemas e enfrentá-los requer união de forças e dever de todos nós. Não deixemos faltar otimismo e a valorização das instituições, e o SUS é uma grande representante brasileira.

\section{REFERÊNCIAS}

ATLAS BRASIL. Atlas do desenvolvimento humano. 2013. Disponível em: $<$ htpp://atlasbrasil.org.br/>. Acesso em: 13 fev. 2016.

BRASIL - CNES. Cadastro Nacional de Estabelecimentos de Saúde 2015. 2015. Disponível em: <http://cnes.datasus.gov.br/pages/estabelecimentos/consulta.jsp>. Acesso em 10.fev.2016.

CLIMATE-data. Disponível em: <htpp://pt.climate-data.org/>. Acesso em: 24 mar. 2016.

IBGE. Instituto Brasileiro de Geografia e Estatisticas. Censo Demográfico 2010. Características da população e dos domicílios: resultados do universo. Rio de Janeiro: IBGE, 2010. Disponível em: <http://censo2010.ibge.gov.br/>. Acesso em: 20 jan. 2016.

MANDAJ, V. Análise da Saúde Pública no Município de Taboão da Serra-SP. (Trabalho de Conclusão de Curso) - Universidade de São Paulo, São Paulo, 2016.

MENDES, A. A importância da avaliação do financiamentos gasto do SUS realizado pelos municípios: a contribuição do SIOPS. São Paulo: Domingueira da Saúde, 2016.

OBSERVATÓRIO IPPUR/ UFRJ-FASE. Divisão político-administrativa da RM. 2000. Disponível em:

<http://www.observatoriodasmetropoles.ufrj.br/imagens/rm_sp.gif>. Acesso em: 20 jan. 2016.

PREFEITURA MUNICIPAL DE TABOÃO DA SERRA. Disponível em: $<$ htpp://taboaodaserra.sp.gov.br/>. Acesso em: 20 jan. 2016.

PREFEITURA MUNICIPAL DE TABOÃO DA SERRA. Secretaria de Saúde. Rede Pública de Saúde de Taboão da Serra. Estrututa da Secretaria de Saúde. Disponivel em <htpp://taboaodaserra.sp.gov.br/>. Acesso em: 20 jan. 2016.

PREFEITURA MUNICIPAL DE TABOÃO DA SERRA.. Secretaria de Educação e Cultura. Cenas da cidade: Taboão da Serra 1918 a 1980. São Paulo: Nativa; 2004. Disponível em <http://ts.sp.gov.br/secretarias/educacao-ciencia-e-tecnologia>. Acesso em: 20 jan. 2016. 
ROCHA, A. A; CÉSAR, C. L. G; RIBEIRO, H. Saúde Pública: bases conceituais. 2. ed. São Paulo: Atheneu, 2013.

SARGSUS. Sistema de Apoio ao Relatório Anual de Gestão. 2012. Disponível em: <http://datasus.saude.gov.br/>. Acesso em: 10 mar. 2016.

SEADE. Disponível em: <http://www.seade.gov.br/>. Acesso em fevereiro de 2016.

SEADE. Estimativa da população de Taboão da Serra. Disponível em: $<$ http://www.seade.gov.br/>. Acesso em fev.2015.

SIOPS - Sistema de Informações sobre Orçamentos Públicos em Saúde. 2015.

Disponível em: <http://siops.datasus.gov.br/>. Acesso em: 12 mar. 2016. 